\title{
AVALIAÇÃO DO PROCESSO PRODUTIVO DE UMA INDÚSTRIA DE MANUFATURA DE PAINÉIS POR MEIO DO BALANÇO DE MATERIAL E DO RENDIMENTO DA MATÉRIA-PRIMA ${ }^{1}$
}

\author{
Martha Andreia Brand ${ }^{2}$, Umberto Klock ${ }^{3}$, Graciela Inês Bolzon de Muñiz ${ }^{3}$, Dimas Agostinho da Silva ${ }^{3}$
}

\begin{abstract}
RESUMO - O trabalho foi desenvolvido no setor de manufatura de painéis da Battistella Indústria e Comércio Ltda., localizada em Santa Catarina, e teve como objetivo a avaliação do processo produtivo de painéis, utilizandose os princípios do balanço de material e do rendimento da matéria-prima. Além disso, pretendeu-se estabelecer uma metodologia para aplicação em outras indústrias madeireiras. Os dados foram obtidos através de visitas, aplicação de questionários e dados de escritório, e elaboraram-se equações e um fluxograma para representar o balanço de material. Concluiu-se que a indústria é integrada, representando vantagem competitiva. $\mathrm{O}$ balanço de material indicou que a atividade com maior potencial gerador de resíduos foi a preparação de sarrafos de madeira $(55,71 \%$ do total de resíduos gerados). As atividades com maiores rendimentos foram a prensagem $(97,44 \%)$, o seccionamento $(93,92 \%)$, o esquadrejamento $(93,51)$, o lixamento $(90,97 \%)$ e a preparação de sarrafos $(54,51 \%)$. O rendimento geral da manufatura foi de $63,16 \%$, sendo os valores encontrados no trabalho similares aos da literatura. A metodologia desenvolvida para o trabalho é simples e pode ser aplicada em outras indústrias do setor madeireiro.
\end{abstract}

Palavras-chave: Balanço de material, manufatura de painéis, resíduos, rendimento.

\section{EVALUATION OF THE PRODUCTIVE PROCESS OF A PANEL MANUFACTURING INDUSTRY THROUGH MATERIAL BALANCE AND THE RAW-MATERIAL YIELD}

\begin{abstract}
The present study aimed at evaluating the productive process of panels, using the principles of material balance and the yield of wood raw material, in order to establish a methodology to be applied in other wood industries. This work was carried out in the panel-manufacturing sector of Battistella Indústria e Comércio Ltda, State of Santa Catarina. Data were obtained by means of visits, questionnaire application and office data. In order to represent the material balance some equations and a flowchart were produced. Based on these data, it was possible to conclude that the industry is integrated, fact that represents a competitive advantage. The material balance indicated that the activity with the highest potential to produce waste was wood lath preparation (55,71\% from all the waste); the activities with the highest yield were pressing $(97,44 \%)$ followed by sectioning (93,92\%); boarding (93,51\%); sandpapering (90,97\%) and lath preparation (54,51\%). The overall yield of manufacturing was $63,16 \%$. These values were similar to those found in the literature. The methodology developed in this study is simple and may be applied to any other industry of the wood sector.
\end{abstract}

Key words: Material balance, panels manufacturing, wood waste and yield.

\footnotetext{
${ }^{1}$ Recebido para publicação em 10.3.2003 e aceito para publicação em 10.8.2004.

${ }^{2}$ Departamento de Ciências Exatas e Tecnológicas da UNIPLAC. <martha@uniplac.net>.

${ }^{3}$ Departamento de Engenharia e Utilização de Produtos Florestais da UFPR.<klockuer@floresta.ufpr.br/gbmunize@barigui.ufpr.br /dimass@floresta.ufpr.br>
} 


\section{INTRODUÇÃO}

$\mathrm{O}$ fato de as indústrias de base florestal gerarem grandes quantidades de resíduos no processo produtivo não é novidade. Porém, o aumento progressivo da quantidade de madeira desdobrada tem revelado o problema da disponibilização de quantidades ainda maiores de resíduos, que muitas vezes não têm utilização na indústria onde foram gerados.

Estimativas grosseiras da quantidade de resíduos disponíveis podem ser feitas através das áreas florestais produtivas, da sua produção primária e do grau de rendimento. Nos resíduos das diferentes indústrias madeireiras, a disponibilidade pode ser determinada diretamente das estatísticas disponíveis ou da relação input matéria-prima output produtos (PATZAK, 1977).

As indústrias de produtos secundários de madeira incluem empresas que manufaturam produtos acabados de tábuas ou lâminas produzidas pela indústria primária. Como exemplos, podem-se citar móveis; divisórias de escritórios; produtos manufaturados para o comércio, como janelas, portas, armários, pisos, cercas; pallets; produtos para construção; etc. Essas empresas podem dar acabamento ao produto final, como também serrar ou dimensionar a madeira serrada. A quantidade de resíduos de madeira produzida varia muito com o tipo de atividade, os quais podem ser pequenos ou grandes, incluindo partículas, serragem, refilos, destopos e uma combinação destes (C.T.DONOVAN ASSOCIATES INC., 1990).

Kock (1976) determinou o rendimento da fabricação de compensados de coníferas, bem como a destinação dos resíduos. Segundo esse autor, de uma tonelada de tora sem casca, obtêm-se $0,45 \mathrm{t}$ de compensado sem lixamento (incluindo cola); 0,06 t de lâminas aplainadas para uso em miolos de painéis; $0,08 \mathrm{t}$ de partículas para uso em chapas de partículas; $0,30 \mathrm{t}$ de partículas para uso em polpa; e 0,12 t de partículas para uso como combustível.

Ekono (1980), a exemplo de Kock (1976), também avaliou rendimento, perdas e possível destinação dos resíduos de folhosas em indústrias de compensado nas Filipinas. Ele chegou à conclusão de que uma tonelada de toras pode produzir $0,47 \mathrm{t}$ de compensado, $0,36 \mathrm{t}$ de partículas para uso em chapas de partículas, 0,07 t de perdas e $0,10 \mathrm{t}$ de partículas para uso como combustível.

R. Árvore, Viçosa-MG, v.28, n.4, p.553-562, 2004
Miyazaki (1989) trabalhou com a quantificação de resíduos na indústria de compensados no Japão, onde a matéria-prima são toras de madeiras duras importadas. $\mathrm{Na}$ indústria de compensados, a produção de resíduos foi de $0,80 \%$ na forma de serragem, $1,90 \%$ de destopo, $6,60 \%$ de rolo-resto, $9,30 \%$ de lâminas verdes provenientes do início da laminação das toras, $4,40 \%$ de lâminas secas, 3,20\% de resíduos de compensados, $1,20 \%$ de pó-de-lixa e $0,30 \%$ de casca, totalizando $27,70 \%$ de resíduos no processo produtivo total.

$\mathrm{Na}$ indústria de compensados, o resíduo gerado tem a mesma destinação do gerado na serraria e na indústria de assoalho, sendo quase todos os resíduos consumidos como combustível (MIYAZAKI, 1989).

Andrade (1992), estudando fábricas de compensados na Malásia e Indonésia, encontrou perdas de $53 \%$ no processo produtivo, das quais, porém, $43 \%$ estavam relacionadas às atividades de laminação $e$ classificação das lâminas e somente 7,5\% eram relativas ao esquadrejamento e $3,0 \%$ ao lixamento dos painéis.

No Brasil, Tomaselli (1992), que avaliou a produção de compensados a partir de espécies tropicais, encontrou rendimento médio de $38 \%$, quando usadas espécies de várzea e $42 \%$ quando utilizadas espécies de terra firme. No entanto, esses resultados foram obtidos a partir das toras no pátio, considerando-se toda a atividade de laminação.

Olandoski (2001) avaliou uma indústria de compensados, sarrafeados e aglomerados revestidos feitos a partir de madeira tropical, no sul do Brasil, quanto à produção de resíduos e ao rendimento produtivo. Como resultados desse trabalho, sua autora encontrou, na produção de compensados, rendimentos de 95 a $97 \%$ nas esquadrejadeiras, $91 \%$ na lixadeira e $91 \%$ na refiladeira e encoladeira.

Em trabalho realizado por Silva (2001) também na região sul do Brasil, em indústria de compensados de Pinus, ele constatou que se produzir $1,9 \mathrm{~m}^{3}$ de resíduos para cada $\mathrm{m}^{3}$ de compensados, considerando a laminação e as atividades de manufatura dos painéis. Mencionou ainda que a produção de resíduos é de $65 \%$ quando considerado todo o processo produtivo (laminação e manufatura). Porém, de todo o resíduo gerado, $89 \%$ é produzido na laminadora e apenas $11 \%$, na fábrica.

No Estado do Paraná, o rendimento médio pon- 
derado nas indústrias de chapas compensadas é de $36,52 \%$, em que as maiores perdas ocorrem no processo de laminação. Na manufatura, a esquadrejadeira tem um rendimento de $89,8 \%$ e a lixadeira, $95,6 \%$ (BONDUELLE et al., 2004).

$\mathrm{Na}$ indústria de painéis sarrafeados, Ecker et al. (2003) encontraram 43,75\% de rendimento no processo produtivo, partindo de sarrafos verdes até o painel acabado. Assim, fica clara a necessidade da caracterização do processo produtivo para o melhor aproveitamento da matéria-prima e produção de produtos de melhor qualidade. Dessa forma, este trabalho objetivou a avaliação do processo produtivo de painéis, utilizando os princípios do balanço de materiais e do rendimento da matéria-prima. Além disso, pretendeuse estabelecer uma metodologia simples e que possa ser utilizada em outras indústrias do setor madeireiro.

\section{MATERIAL E MÉTODOS}

Os dados para o trabalho foram coletados na Empresa Battistella Indústria e Comércio Ltda., localizada em Rio Negrinho, Santa Catarina. A indústria utiliza somente madeira de espécies do gênero Pinus, principalmente Pinus taeda L. e Pinus elliottii var. elliottii Engelm., para produzir lâminas e madeira serrada para venda e como matérias-primas para a produção de painéis manufaturados.

A indústria é integrada, ou seja, composta por unidades geradoras de produtos que podem ser vendidos ou utilizados como matéria-prima nos setores subseqüentes. Assim, a sua divisão em setores e a sua análise de forma setorizada possibilitaram o melhor acompanhamento do processo produtivo, tanto dos produtos manufaturados quanto dos resíduos produzidos.

O setor de manufatura de painéis é composto por várias linhas de produção, em que são fabricados painéis compensados, sarrafeados e artefatos de madeira, estando sua composição representada na Tabela 1 .

\subsection{Coleta de dados}

Inicialmente, foram realizadas algumas visitas, as quais tiveram como objetivo o conhecimento e descrição da cadeia produtiva e das características relacionadas à utilização dos resíduos e geração de energia. A partir dessas características, determinou-se que a indústria seria dividida em setores para facilitar o estudo, sendo neste trabalho estudado somente o setor de manufatura de painéis.

Com base nas visitas, foram elaborados questionários, em que se determinou que seria possível a utilização dos dados existentes na empresa. Tais dados constituíram-se em tabelas de consumo e entrada de matéria-prima, compras, produção, estoques e vendas. Assim, foi construída uma série histórica, que compreendeu um intervalo de 18 meses, desde janeiro de 1998 até julho de 1999.

Tabela 1 - Equipamentos e atividades componentes da manufatura de painéis Table 1 - Machines and component activities of panel manufacturing

\begin{tabular}{lcl}
\hline Equipamento ou atividade & Quant. & \multicolumn{1}{c}{ Descrição } \\
\hline Classificação de madeira serrada & 01 & Classificação da madeira saída do secador \\
Plainas & 08 & Preparação de sarrafos para os painéis \\
& 02 & Preparação de quadradinho \\
Destopadeira & 02 & Preparação de sarrafos para os painéis \\
(Serra circular) & 02 & Preparação de quadradinho \\
& 10 & Preparação de pré-cortados \\
Coladeira & 08 & Produção de miolo para painel sarrafeado revestido e painel \\
& 02 & sarrafeado multilaminado \\
Prensa passadeira de cola & & Produção de compensado, painel multilaminado e revestimento \\
& 02 & de painel sarrafeado \\
Esquadrejadeira & 01 & Determinação das dimensões finais dos painéis \\
Setor de emassamento & 01 & Acabamento dos painéis \\
Lixadeira & 01 & Desdobramento de painéis em dimensões menores \\
Seccionadora & 01 & Classificação dos painéis \\
Setor de classificação & 01 & Embalagem e carregamento de produtos \\
Setor de expedição &
\end{tabular}




\subsection{Determinação do rendimento e dos resíduos do processo produtivo}

A determinação do rendimento do processo produtivo foi feita com base no princípio do balanço de material, que consiste na determinação de todas as entradas (matéria-prima, compra de material e estoques) e saídas (produtos intermediários e finais, vendas de produtos e resíduos), e também com base no rendimento, que é a relação porcentual entre a quantidade de produto que sai do processo e a quantidade de matéria-prima que entra no processo.

As equações elaboradas para a determinação dos rendimentos do processo produtivo e a geração de resíduos estão representadas na Tabela 2. Porém, para o balanço de material não foram considerados todos os insumos que entram na produção (adesivos, resinas etc.), limitando-se apenas à avaliação da madeira.

Outro aspecto que deve ser observado é o fato de serem consideradas na avaliação somente as operações que geram resíduos ou perdas, ficando de fora o emassamento que não gera nenhuma perda ou desperdício. Além disso, na venda de produtos (saída) foram consideradas somente aquelas realizadas durante as fases intermediárias do processo. Dessa forma, as vendas de painéis acabados não foram consideradas neste estudo.

\subsection{Elaboração do fluxograma do balanço de material}

Para possibilitar a avaliação do balanço de material da indústria foi elaborado um fluxograma (Figura 1). O fluxograma inicia com a entrada da matéria-prima (lâminas e madeira serrada). A partir dai, a seqüência do processo é dada sempre pela atividade ou equipamento envolvido no processo produtivo (coladeira, prensa etc.).

A matéria-prima, após a passagem pela atividade produtiva, terá dois caminhos. O lado esquerdo do fluxograma é destinado à saída dos produtos e sua destinação (venda e, ou, estoque) e o lado direito, à saída dos resíduos gerados durante o processo e sua destinação (venda e, ou, geração de energia).

Cada item do fluxograma contém a média mensal do período, representada pela letra " $x$ ". Após a média mensal é colocado um valor percentual correspondente ao rendimento que está vinculado à atividade e não ao produto, pois não é possível a determinação do rendimento deste em cada fase. Isso é devido ao fato de que entram várias matérias-primas em um mesmo equipamento ou etapa do processo produtivo, saindo também vários produtos.

\section{RESULTADOS E DISCUSSÕES}

Nos balanços de material das Figuras 2, 3 e 4, os pontos de referência de entradas e saídas são as coladeiras, prensas, esquadrejadeiras, lixadeiras, processo de classificação e seccionadoras, ficando de fora a classificação de madeira e a operação de emassamento, com a ressalva de que esta última não contribui e não altera o fluxograma.

Na coladeira está incluída a atividade de preparação dos sarrafos, tanto de madeira sólida quanto de painéis multilaminados, que antecede a operação de colagem lateral dos tapetes dos painéis sarrafeados.

Nessa atividade, como nas demais etapas do processo, o resíduo poderá ter dois destinos, a venda ou a geração de energia. Assim, todo o resíduo gerado pelos cortes das serras (serragem e pó-de-lixa) são captados por exaustores, instalados sobre cada equipamento de corte, que levam o material para um silo, do qual sai para a venda. Os demais resíduos gerados e que têm dimensões maiores caem nas correias transportadoras, instaladas sob os equipamentos, que levam o material para um picador e, posteriormente, para a caldeira.

$\mathrm{Na}$ Figura 2, tanto o painel sarrafeado sem revestimento (poliplac) quanto o painel sarrafeado multilaminado (lamiplac) saem da coladeira como produtos acabados diretamente para a expedição. $\mathrm{O}$ miolo segue para a prensa, e nessa etapa entram as lâminas secas e classificadas para a composição dos compensados e painéis multilaminados e para o revestimento do miolo (painel sarrafeado), que neste ponto passa a ser denominado painel sarrafeado revestido ("blockboard").

Da prensa, os painéis passam obrigatoriamente pelo esquadrejamento, representado na Figura 3. A operação de lixamento somente é realizada nos painéis compensados e sarrafeados revestidos, enquanto os paineís multilaminados seguem até a seccionadora para a confecção de tábuas destinadas à preparação dos sarrafos para a composição do painel sarrafeado multilaminado, na coladeira. 
Tabela 2 - Equações do balanço de materiais e do rendimento Table 2 - Equations of material balance and yield

\begin{tabular}{|c|c|}
\hline Consumo matéria-prima & Variáveis envolvidas \\
\hline Chapas manufaturadas & $\mathrm{m}^{3}$ madeira e lâmina $\mathrm{p} /$ produção de painéis $=100 /$ rendim. geral da manufatura \\
\hline Rendimento (\%) & Variáveis envolvidas \\
\hline Classificação de madeira serrada & $\begin{array}{l}\text { Rendimento }=(\text { volume de madeira classificada }) /(\text { volume de madeira saída do secador } \\
+ \text { estoque anterior de madeira seca }+ \text { volume de madeira seca comprada }- \text { volume de } \\
\text { madeira bruta vendida }) \text { x } 100\end{array}$ \\
\hline Preparação de sarrafos e coladeira & $\begin{array}{l}\text { Rendimento }=((\text { volume de miolo }+ \text { volume de painel sarrafeado }+ \text { volume de painel } \\
\text { sarrafeado multilaminado que saem da coladeira }) /(\text { volume de madeira e painel multilaminado } \\
\text { que entram na coladeira })) \times 100\end{array}$ \\
\hline Prensas & $\begin{array}{l}\text { Rendimento }=((\text { volume de painel multilaminado }+ \text { volume de compensado }+ \text { volume } \\
\text { de painel sarrafeado revestido que saem das prensas }) /(\text { volume de miolo }+ \text { volume de } \\
\text { lâminas que entram nas prensas })) \times 100\end{array}$ \\
\hline Esquadrejadeira & $\begin{array}{l}\text { Rendimento }=((\text { volume de painel multilaminado }+ \text { volume de compensado }+ \text { volume } \\
\text { de painel sarrafeado revestido que saem da esquadrejadeira }) /(\text { volume de painel multilaminado } \\
+ \text { volume de compensado }+ \text { volume de painel sarrafeado revestido que entram na } \\
\text { esquadrejadeira }) \times 100\end{array}$ \\
\hline Lixadeira & $\begin{array}{l}\text { Rendimento }=((\text { volume de compensado }+ \text { volume de painel sarrafeado revestido que } \\
\text { saem da lixadeira }) /(\text { volume de compensado }+ \text { volume de painel sarrafeado revestido que } \\
\text { entram na lixadeira }) \times 100\end{array}$ \\
\hline Seccionadora & $\begin{array}{l}\text { Rendimento }=((\text { volume de painel multilaminado }+ \text { volume de compensado }+ \text { volume } \\
\text { de painel sarrafeado revestido que saem da seccionadora }) /(\text { volume de painel multilaminado } \\
+ \text { volume de compensado }+ \text { volume de painel sarrafeado revestido que entram na } \\
\text { seccionadora }) \times 100\end{array}$ \\
\hline Manufatura (geral) & $\begin{array}{l}\text { Rendimento geral = (volume de painel classificado/volume de madeira e lâminas que } \\
\text { entram na manufatura }) \times 100\end{array}$ \\
\hline Resíduos g & Variáveis envolvidas \\
\hline Classificação de m & $\begin{array}{l}\text { Resíduos }=\text { (volume de madeira saída do secador }+ \text { estoque anterior de madeira seca }+ \\
\text { volume de madeira seca comprada) - (volume de madeira classificada }+ \text { volume de madeira } \\
\text { bruta vendida) }\end{array}$ \\
\hline Preparação de sarrafos (madeira) & $\begin{array}{l}\text { Resíduos = volume de madeira que entra nas plainas }-(\text { volume de miolo saído da coladeira } \\
+ \text { volume de painel sarrafeado saído da coladeira })\end{array}$ \\
\hline $\begin{array}{l}\text { Preparação de sarrafos } \\
\text { (painel multilaminado) }\end{array}$ & $\begin{array}{l}\text { Resíduos = volume de painel multilaminado que entra nas plainas - volume de painel } \\
\text { sarrafeado multilaminado saído da coladeira }\end{array}$ \\
\hline Prensas ${ }^{1}$ & $\begin{array}{l}\text { Resíduos }=(\text { volume de miolo }+ \text { volume de lâminas que entram na prensa })-(\text { volume } \\
\text { de painel multilaminado }+ \text { volume de compensado }+ \text { volume de painel sarrafeado revestido } \\
\text { que saem das prensas })\end{array}$ \\
\hline Esquadrejadeira & $\begin{array}{l}\text { Resíduos }=(\text { volume de painel multilaminado }+ \text { volume de compensado }+ \text { volume de painel } \\
\text { sarrafeado revestido que entram na esquadrejadeira })-(\text { volume de painel multilaminado } \\
+ \text { volume de compensado }+ \text { volume de painel sarrafeado revestido que saem da esquadrejadeira })\end{array}$ \\
\hline Lixadeira & $\begin{array}{l}\text { Resíduos }=(\text { volume de compensado }+ \text { volume de painel sarrafeado revestido que entram } \\
\text { na lixadeira }) \text { - (volume de compensado }+ \text { volume de painel sarrafeado revestido que } \\
\text { saem da lixadeira })\end{array}$ \\
\hline Seccionadora & $\begin{array}{l}\text { Resíduos }=(\text { volume de painel multilaminado }+ \text { volume de compensado }+ \text { volume de painel } \\
\text { sarrafeado revestido que entram na seccionadora })-(\text { volume de painel multilaminado } \\
+ \text { volume de compensado }+ \text { volume de painel sarrafeado revestido que saem da seccionadora })\end{array}$ \\
\hline Resíduos gerados por $\mathrm{m}^{3}$ & Variáveis envolvidas \\
\hline
\end{tabular}

$\mathrm{m}^{3}$ de resíduos $/ \mathrm{m}^{3}$ chapas manufaturadas $=($ volume de madeira e lâminas que entram no processo para a geração de $1 \mathrm{~m}^{3}$ de chapa manufaturada $-1 \mathrm{~m}^{3}$ de chapa manufaturada)

1 - O resíduo gerado nas prensas é somente devido à compressão, não gerando resíduos destinados à geração de energia.

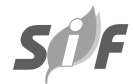

R. Árvore, Viçosa-MG, v.28, n.4, p.553-562, 2004 


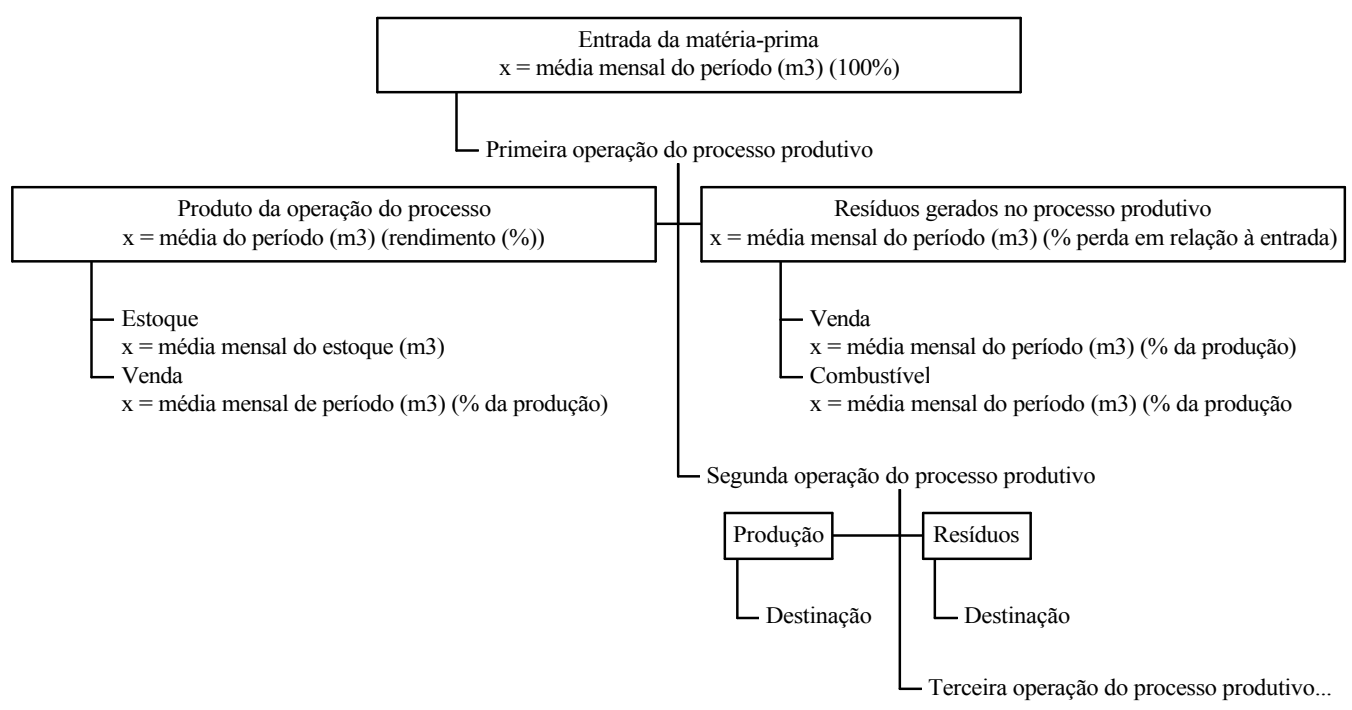

Figura 1 - Fluxograma do balanço de material.

Figure 1 -Flowchart for the material balance.

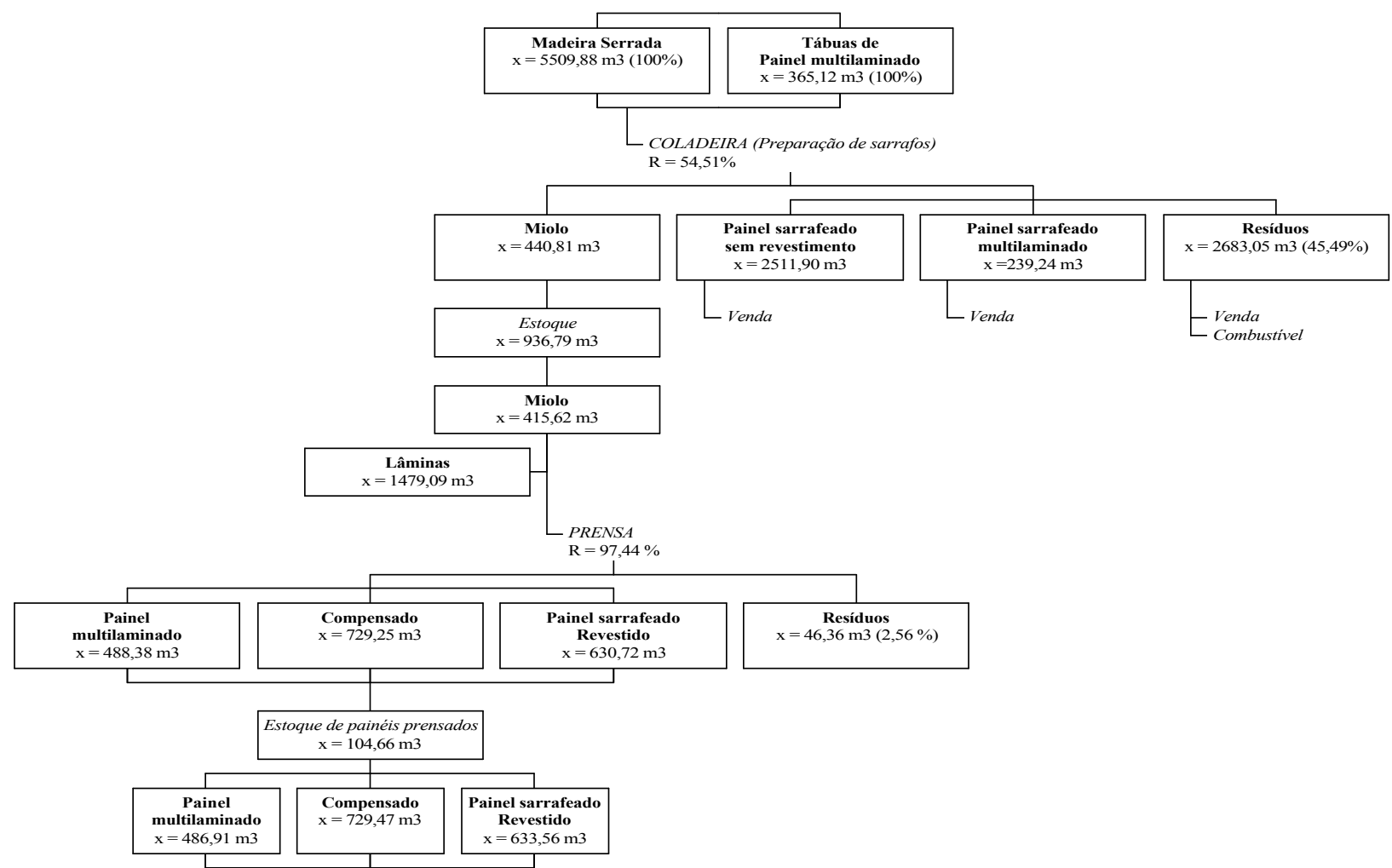

Figura 2 - Balanço de material - Manufatura de painéis (parte 1).

Figure 2 - Material balance - Panel manufacturing (1).

R. Árvore, Viçosa-MG, v.28, n.4, p.553-562, 2004 


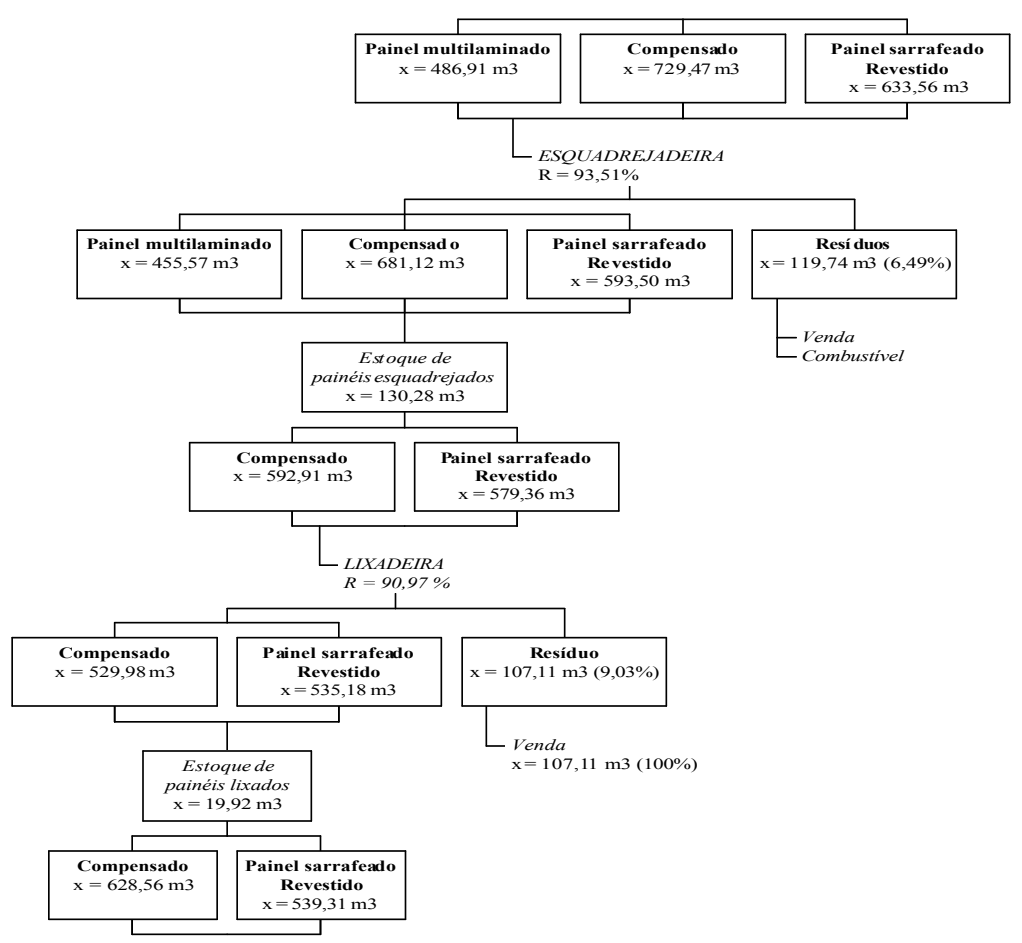

Figura 3 - Balanço de materiais - Manufatura de painéis (parte 2). Figure 3 - Material balance - Panel manufacturing (II).

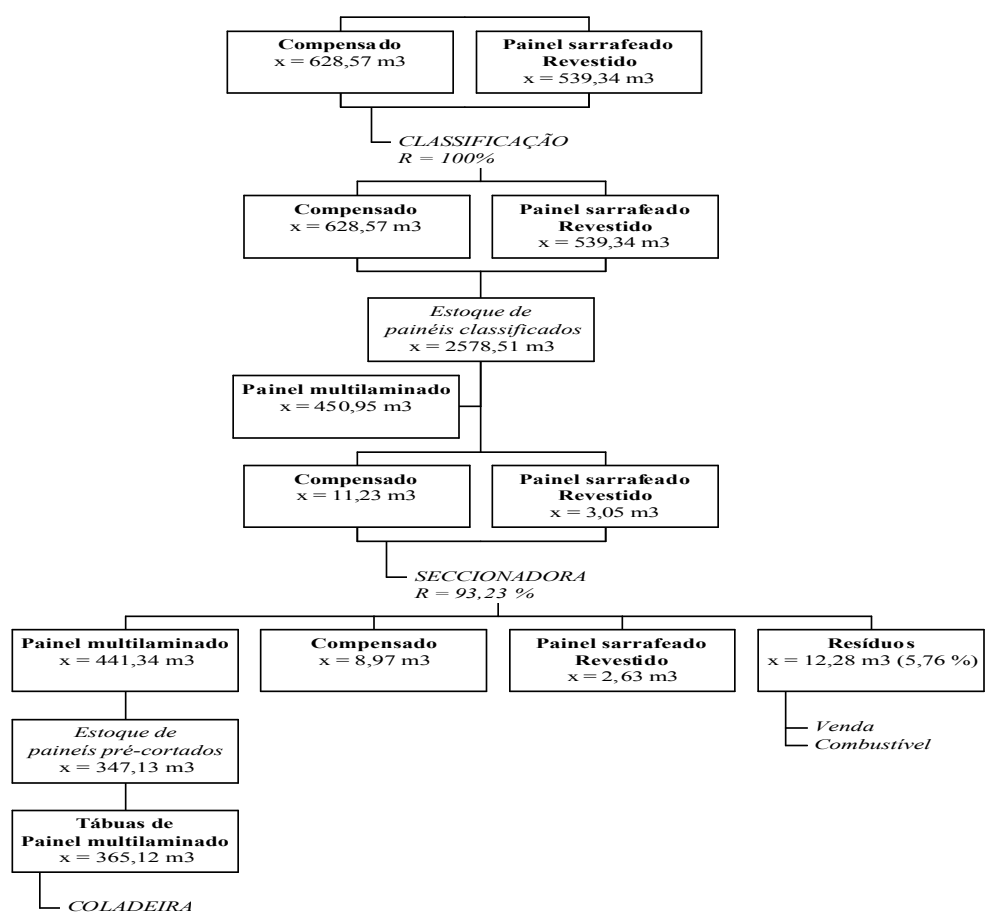

Figura 4 - Balanço de materiais - Manufatura de painéis (parte 3).

Figure 4 - Material balance - Panel manufacturing (III). 
Depois do lixamento, os painéis compensados e sarrafeados revestidos passam pela classificação (Figura 4), e a maior parte deles é destinada à expedição, ressaltando-se que apenas uma pequena parcela segue para a seccionadora.

Através dos fluxogramas das Figuras 2,3 e 4, podese perceber que os pontos geradores de resíduos são a preparação de sarrafos, esquadrejadeira, lixadeira e seccionadora, sendo as perdas observadas nas prensas somente devidas à compressão, e a atividade de classificação dos painéis tem rendimento de $100 \%$. A lixadeira é o único ponto onde todo o resíduo gerado é destinado para a venda.

A partir dos dados das Figuras 2, 3 e 4 foi elaborada a Tabela 3, para a melhor avaliação do rendimento das etapas do processo e do rendimento geral da manufatura de painéis, bem como para facilitar as discussões acerca dos resultados.

O rendimento de cada etapa do processo produtivo da manufatura de painéis é maior que em processos de transformação primária, como em laminadoras e serrarias, porque nesse setor as atividades são características de acabamento de produtos, pois estes estão semi-acabados. Conseqüentemente, o rendimento geral desse setor é maior.

Assim, com base no valor do rendimento geral da manufatura de painéis, foi possível definir que, para a produção de $1 \mathrm{~m}^{3}$ de painel manufaturado, é necessário $1,63 \mathrm{~m}^{3}$ de lâminas secas e classificadas e madeira serrada classificada (DP - 0,27). Silva (2001), conforme mencionado anteriormente, encontrou o valor de $1,9 \mathrm{~m}^{3}$ de resíduos para cada $\mathrm{m}^{3} \mathrm{de}$ compensado. Os valores dos dois trabalhos têm grande diferença, porque o autor avaliou desde a laminação até a manufatura do produto, enquanto o resultado encontrado neste trabalho restringe-se à utilização de lâminas de madeira secas e classificadas (considera somente as atividades de manufatura). Os valores obtidos por autores, que também trabalharam com a indústria de transformação secundária da madeira, são apresentados na Tabela 4.

Para a realização das comparações foi utilizado o valor de rendimento geral da laminadora da empresa aqui avaliada, determinado em estudo anterior. $\mathrm{O}$ rendimento médio foi de 40,71\% ((volume de lâmina seca classificada que sai da laminadora/volume de toras com casca que entra no torno laminador) x 100).

Analisando a Tabela 4, pode-se dizer que o rendimento geral da manufatura de painéis compensados, da indústria estudada neste trabalho, está próximo, mas inferior aos valores encontrados por Tomaselli (1992), Silva (2001) e Bonduelle et al. (2004).

O rendimento somente das operações de manufatura dos compensados (esquadrejamento, lixamento e seccionamento) foi inferior aos encontrados na literatura. Porém, os autores não mencionaram a operação de seccionamento, e se esta for retirada o rendimento aumenta para $84,48 \%$, aproximando-se mais dos valores da literatura.

Nas operações de esquadrejamento, o valor do trabalho aproxima-se do de Andrade (1992) e Olandoski (2001), enquanto no lixamento se aproxima do de Olandoski (2001).

Tabela 3 - Dados médios de cada operação do processo de manufatura durante o período avaliado (1998/1999)

Table 3 - Average data of the manufacturing process operation during the evaluated period (1998/1999)

\begin{tabular}{|c|c|c|c|c|c|c|c|c|}
\hline \multirow[t]{2}{*}{ Operação } & \multicolumn{2}{|c|}{$\begin{array}{c}\text { Entrada } \\
\text { matéria-prima }\left(\mathrm{m}^{3}\right)\end{array}$} & \multicolumn{2}{|c|}{$\begin{array}{c}\text { Saída do } \\
\text { produto }\left(\mathrm{m}^{3}\right)\end{array}$} & \multicolumn{2}{|c|}{$\begin{array}{c}\text { Saída de } \\
\text { resíduo }\left(\mathrm{m}^{3}\right) \\
\end{array}$} & \multicolumn{2}{|c|}{$\begin{array}{c}\text { Rendimento } \\
\text { da produção (\%) }\end{array}$} \\
\hline & Média & DP & Média & DP & Média & DP & Média & DP \\
\hline $\begin{array}{l}\text { Prep. Sarrafos/ } \\
\text { coladeira }\end{array}$ & 5874,99 & 1303,02 & 3191,95 & 674,69 & 2683,05 & 706,70 & 54,51 & 4,25 \\
\hline Prensagem & 1894,71 & 383,44 & 1848,35 & 385,99 & 46,36 & 35,27 & 97,44 & 1,97 \\
\hline Esquadrejamento & 1849,94 & 423,70 & 1730,19 & 398,30 & 119,74 & 26,10 & 93,51 & 0,33 \\
\hline Lixamento & 1172,27 & 425,64 & 1065,16 & 381,00 & 107,11 & 49,59 & 90,97 & 1,76 \\
\hline Seccionamento & 465,23 & 529,06 & 452,94 & 517,82 & 12,28 & 11,56 & 93,92 & 11,33 \\
\hline Geral & 6988,97 & 1213,18 & 4360,39 & 811,80 & 3781,39 & 1075,36 & 63,16 & 12,01 \\
\hline
\end{tabular}

R. Árvore, Viçosa-MG, v.28, n.4, p.553-562, 2004 
Comparando o valor de rendimento do painel sarrafeado com dados obtidos por Ecker et al. (2003), pode-se relatar que o estudo apresentou maior rendimento, por considerar madeira seca e classificada na manufatura, enquanto os outros autores utilizaram madeira verde. Em estudo preliminar a este, na mesma indústria foram obtidos rendimentos de $81,88 \%$ na secagem e $86,42 \%$ na classificação de madeira serrada. Se as perdas desses processos forem descontadas do rendimento para a produção de painéis sarrafeados, pode-se chegar a um valor de rendimento mais próximo da literatura.

Com relação à quantificação e destinação dos resíduos produzidos nesse setor, ver Tabela 5 .

A atividade de manufatura de painéis que mais contribui para a geração de resíduos foi a preparação dos sarrafos de madeira sólida para a coladeira, sendo esse dado bastante coerente, porque essa é a primeira atividade do processo de fabricação de painéis, gerando maior quantidade de resíduos.

A segunda etapa com maior potencial gerador de resíduos foi a classificação de madeiras, também de grande importância, pois todo o resíduo produzido na classificação de madeira é destinado diretamente para a caldeira. Em contrapartida, a etapa com menor geração de resíduos foi a seccionadora, em grande parte pelo pequeno volume de painéis que passa por essa etapa.

Pode-se perceber, na Tabela 5, que apenas pequena parte do resíduo gerado era destinada à venda, representando, em média, $18,66 \%$ do total gerado mensalmente na empresa. $\mathrm{O}$ restante foi destinado à queima na caldeira, para a geração de energias térmica e elétrica.

Tabela 4 - Comparação dos valores de rendimento da indústria secundária da madeira Table 4 - Comparison of yield mean values for the secundary wood industry

\begin{tabular}{|c|c|c|c|c|c|c|}
\hline \multicolumn{5}{|c|}{ Painel compensado laminado } & \multicolumn{2}{|r|}{ P. sarrafeado } \\
\hline Autor & Matéria-prima & Rendimento geral $^{1}$ & $\begin{array}{c}\text { Rendimento } \\
\text { da manufatura }\end{array}$ & Esquadrej. & Lixamento & Rendimento \\
\hline Kock (1976) & Conífera & $\begin{array}{c}51,00 \% \\
\text { (compensado sem lixar) }\end{array}$ & ) & - & - & - \\
\hline Ekono (1980) & Folhosa & $47,00 \%$ & - & - & - & - \\
\hline Miyazaki (1989) & Folhosa & $72,30 \%$ & - & $96,80 \%$ & $98,80 \%$ & - \\
\hline Andrade (1992) & Folhosa & $47,00 \%$ & $81,30 \%$ & $92,50 \%$ & $97,00 \%$ & - \\
\hline Tomaselli (1992) & Folhosa & 38 a $42 \%$ & - & - & - & - \\
\hline Olandoski (2001) & Folhosa & - & - & 95 a $97 \%$ & $91,00 \%$ & - \\
\hline Silva (2001) & Conífera & $35,00 \%$ & $89,00 \%$ & - & - & - \\
\hline Ecker (2003) & Conífera & - & - & - & - & $43,75 \%^{6}$ \\
\hline Bonduelle et al. (2004) & Ambas & $36,52 \%$ & - & $89,80 \%$ & $95,60 \%$ & - \\
\hline Dados do trabalho ${ }^{2}$ & Conífera & $\begin{array}{l}37,03 \%^{3} \\
33,27 \%^{4}\end{array}$ & $77,71 \%{ }^{5}$ & $93,51 \%$ & $90,97 \%$ & $63,16 \%^{7}$ \\
\hline
\end{tabular}

${ }^{1}$ Inclui operações de laminação e manufatura $;{ }^{2}$ dados obtidos na análise do intervalo de janeiro de 1998 a julho de $1999 ;{ }^{3}$ toras até compensado sem lixar; ${ }^{4}$ toras até compensado acabado, ${ }^{5}$ incluindo esquadrejamento, lixamento e seccionamento, ${ }^{6}$ produção a partir de sarrafos verdes; e ${ }^{7}$ produção a partir de madeira seca e classificada.

Tabela 5 - Valores médios mensais dos resíduos gerados na manufatura de painéis Table 5 -Mean monthly values of wood waste produced by panel manufacturing

\begin{tabular}{|c|c|c|c|c|c|c|}
\hline \multirow[t]{2}{*}{$\overline{\text { Atividade }}$} & \multicolumn{2}{|c|}{$\begin{array}{l}\text { Volume de } \\
\text { resíduo gerado }\end{array}$} & \multicolumn{2}{|c|}{$\begin{array}{l}\text { Participação do total de } \\
\text { resíduo gerado }(\%)\end{array}$} & \multirow[t]{2}{*}{$\begin{array}{l}\text { Volume } \\
\text { vendido }\end{array}$} & \multirow[t]{2}{*}{$\begin{array}{r}\text { Volume } \\
\text { queimado } \\
\end{array}$} \\
\hline & Média & DP & Média & DP & & \\
\hline Classificação de madeira & 1667,79 & 774,65 & 36,34 & 11,15 & & 1667,79 \\
\hline Prep. sarrafos madeira $\mathrm{p} /$ coladeira & 2557,17 & 784,10 & 55,71 & 12,14 & & \\
\hline Prep. sarrafos de painel multilam. $\mathrm{p} /$ coladeira & 125,88 & 156,54 & 2,74 & 4,43 & & \\
\hline Esquadrejadeira & 119,74 & 26,10 & 2,61 & 1,05 & & \\
\hline Lixadeira & 107,11 & 49,59 & 2,33 & 1,45 & 107,11 & \\
\hline Seccionadora & 12,28 & 11,56 & 0,27 & 0,34 & & \\
\hline TOTAL & 4589,96 & & 100 & & 808,58 & 3781,39 \\
\hline
\end{tabular}




\section{CONCLUSÕES}

a) A indústria é integrada, possuindo uma laminadora e uma serraria para suprir o processo produtivo da manufatura de painéis com matéria-prima, característica pouco comum no setor madeireiro, mas que representa vantagem competitiva.

b) No balanço de material da manufatura de painéis, a atividade com maior rendimento foi a prensagem, mas que não gera resíduos madeiráveis, seguida do seccionamento, esquadrejamento, lixamento e preparação de sarrafos para coladeira.

c) A atividade que contribuiu com a maior quantidade de resíduos foi a preparação de sarrafos de madeira sólida, seguida da classificação de madeira serrada.

d) De maneira geral, os rendimentos obtidos neste trabalho foram similares ao encontrados na literatura.

e) A metodologia utilizada neste trabalho é simples e pode ser extrapolada em outros estudos de indústrias do setor madeireiro.

\section{AGRADECIMENTO}

À UFPR, pela oportunidade de realização do trabalho; à CAPES, pela bolsa de estudos; e à empresa Battistella Indústria e Comércio Ltda., pelo fornecimento dos dados.

\section{REFERÊNCIAS BIBLIOGRÁFICAS}

ANDRADE, A.U. Tecnologias modernas para a fabricação de compensados. In: ENCONTRO INTERNACIONAL DE COMPENSADOS DE MADEIRA TROPICAL, 1., 1992, Manaus. Anais... Manaus: 1992. p 117-123.

BONDUELLE, G.M.; CHIES, D.; MARTINS, D.G.O processo de fabricação de painéis compensados no Estado do Paraná, analisado através dos rendimento e dos resíduos gerados. Disponível em < http:/ /www.remade.com.br > Acesso em: abril de 2004.

C.T.DONOVAN ASSOCIATES INC. Opportunities and Constraints associated with using wood waste for fuel in connecticut. Connecticut: Office of Policy and Management, Energy Division, 1990.
ECKER, V.; CUNHA A.B.; MODESTI, L.G. Avaliação do processo produtivo de uma indústria de painéis sarrafeados. In: CONGRESSO FLORESTAL BRASILEIRO, 8., 2003, São Paulo. Anais... São Paulo: 2003. p. 313-314.

EKONO. Power and heat plants. Estudo preparado para a FAO, portfolio de indústrias florestais de pequeno porte para os países em desenvolvimento. Finlândia: 1980.

KOCK, P. Material balances and energy required for manufacture of ten wood commodities. ENERGY and the wood products industry. Georgia: Forest Products Research Society, 1976. 173p.

MIYAZAKI, M. Forestry products and waste. In: KITANI, O.; HALL, C.W. (Eds.) Biomass handbook. New York: Gordon and Breach Science Publishers, 1989. p. 160-170.

OLANDOSKI, D.P. Rendimento, resíduos e considerações sobre melhorias no processo em indústrias de chapas compensadas. 2001,85 f. Dissertação (Mestrado em Ciências Florestais). Universidade Federal do Paraná, Curitiba, 2001.

TOMASELLI, I. Introdução de espécies pouco conhecidas na indústria de compensados da Amazônia. In: ENCONTRO INTERNACIONAL DE COMPENSADOS DE MADEIRA TROPICAL, 1., 1992, Manaus. Anais... Manaus: 1992. p 73-94.

PATZAK, W. Energia da madeira e de resíduos: estágio atual da pesquisa e da prática na Alemanha ocidental. In:SEMINÁRIO FLORESTA: POTENCIAL ENERGÉTICO BRASILEIRO, 1977. p. 73-83.

SILVA, D.A. Avaliação da eficiência energética de uma indústria de painéis compensados. 2001. 205f. Tese (Doutorado em Ciências Florestais). Universidade Federal do Paraná, Curitiba, 2001. 